DOI 10.14526/2070-4798-2018-13-4-23-30

\title{
Pedagogical interpretation of information about biomechanical characteristics of sprinting among female athletes
}

\author{
Aleksey V. Meshcheryakov \\ Ulyanov State Pedagogical University, Ulyanovsk, Russia \\ aleksei236632@yandex.ru
}

\begin{abstract}
In terms of general theses, characterizing rational forms of the training process organization an athlete's individuality can be reflected. Methodical rules, which show the essence and the limits of training lessons individualization among qualified athletes, are very urgent. Biomechanical peculiarities reflection of the inner content of movements can be successfully used for pedagogical estimation of an athlete's motor activity state and its development management in the training process. Materials. The article offers a pedagogical interpretation of the information about biomechanical characteristics of sprinting among female athletes of different qualification. Research methods. scientific-methodical literature analysis, sprinting trainers' progressive pedagogical experience summarizing, pedagogical experiment, testing, statistical data handling. Results. A new approach to the training and competitive activity of highly-qualified female track and field athletes is offered. A pedagogical interpretation of the information about biomechanical characteristics of different qualification female sprinters is given. The experimental methodology is created, based on the complex of individual-technical and personal peculiarities of female athletes, which condition competitive activity success. The research results confirmed the hypothesis about qualitative differences in starting stride rhythm as the system of regulated equalities of biochemical characteristics. Two kinds of starting stride rhythm are revealed. The held analysis gave an opportunity to define three main groups of runners with different leading component during 100 meters distance overcoming. The received results about the character of efforts during the supporting reactions, indirectly indicate power potential, can help to define the type of dynamic structure and plan the program of its development. Conclusion. The results of the pedagogical experiment showed the expediency and effectiveness of biomechanical approach use in the running technique estimation, which helped to improve competitive activity indices among qualified female athletes.
\end{abstract}

Keywords: track and field athletics, effectiveness of training, qualified female athletes, sprinting, biomechanics, competitive activity, running technique.

For citations: Aleksey V. Meshcheryakov. Pedagogical interpretation of information about biomechanical characteristics of sprinting among female athletes. The Russian Journal of Physical Education and Sport. 2018; 13 (4): 21-27. DOI 10.14526/2070-4798-2018-13-4-23-30

\section{Introduction}

In modern system of sports training the principles of specialization and individualization are the main ones. In the research works of E.E. Arakelyan and others it is underlined that an athlete's individuality can be effectively demonstrated in terms of general theses, which characterize rational forms of the training process organization $[1,4,6]$. In accordance with this urgent becomes the idea of creating the main methodical rules, which show the essence and the limits of training lessons individualization among qualified athletes. In some methodical materials substantiated recommendations are offered concerning the training process formation depending on many factors, which condition stage-by-stage (long-term) sportsmanship formation $[2,8,9]$.

Modern tendencies analysis, concerning the notions of training highly-qualified athletes, defines the main tendency to the training means part increase, which provide competitive action technical improvement and athletes' special physical readiness (SPR) development at different qualification stages. Another important requirement for training is the effectiveness of training increase, its efficiency coefficient (EC) and aftereffect (cumulative training effect) increase [7,10,11].

1. Biomechanical picture of a person's movements reflects the whole diversity of motor 
function realization in an integrated form. This universal feature of movements inner content biomechanical reflection can be successfully used for pedagogical estimation of an athlete's motor state and its development management during the training process. Many authors pay attention to this important direction at the stage of selection [To reveal informative value of the separate dynamic and kinematic movements characteristics for different aspects of motor function state diagnostics among female athletes-sprinters in order to increase the effectiveness of the training lessons.

2. To determine informative biomechanical characteristics of the running movements for the quality of the separate elements of movements and the effectiveness of their structural organization estimation.

3. To study the indices of qualified female athlete's technical readiness in order to create new, prospective methodologies of young athletes and the nearest reserve of the national team training.

4. To create and then offer to introduce a complex methodology of the main parameters of sprinters' sports-training readiness estimation, including providing it technical means.

\section{Materials and Methods}

The female athletes of different qualifications took part in the research - the $1^{\text {st }}$ category, candidate master of sports, master of sport ( $n=45$, each group had 15 people, age: $17 \pm 1$ years-old). During the research they ran from a low start some control distance with a maximum speed $(60 \mathrm{~m})$. Anthropometric changes were realized according to V.V. Bunak scheme. Quetelet index was calculated. Mass percentage of fat, bone, muscular tissues determination was held according to the corresponding methodology (V.V. Kozlov, A.A. Gladysheva).

Pedagogical experiment was realized in natural conditions of the training process since October, 2017 till July, 2018. During the control exercises fulfillment dynamograms of the support reactions were registered with the help of tensometers, put into the insole of the running boots. The speed of running was registered by means of the time measurement system with the help of electronic chronometer. Spatial characteristics of movements were analyzed according to the materials of high-speed video filming. Comparative analysis of female athletes' biochemical characteristics (of different mastery level) starting stride was held.

\section{Results and Discussion}

During the female athletes' (the 1st category, candidate master of sports, master of sport) anthropometric indices study no valid differences were registered: the female athletes of mentioned above groups don't differ validly in body length $(167,2 \pm 5,2 \mathrm{~cm})$, body mass $(58,11 \pm 2,57 \mathrm{~kg})$. At the same time, with qualification improvement there is some body mass increase, however, these changes are also not valid (P > 0,05). Relative body mass corresponds with the recommended average values for women of this age range $(346-351 \mathrm{~g} / \mathrm{cm})$. Qualified female sprinters have relatively long lower extremities in terms of not long body, at the same time, the ratio of legs length and body length is $53,6 \pm 0,75 \%$. Before the experimental work anthropometric data of female athletes, their biological age, characteristics of special readiness and competitive running structure parameters, female athletes' psychophysiological peculiarities were defined on the basis of complex research works. For the set objectives realization, it is important to reveal informative biomechanical characteristics of the running movements in order to estimate the quality of the separate movements' elements and the effectiveness of their structural organization.

For this purpose, the following characteristics were defined:

- the character of efforts during support reactions;

- time intervals of the flight and amortization support reactions;

- rhythm indices of running parts, phases, periods and running steps;

- speed parameters of locomotions. 
Dynamic and kinematic parameters of the starting stride running steps were studied in order to reveal the factors, which condition the specificity of a rhythmic picture of sprinters' starting speedingup. Dynamic curves of support reactions registration and time intervals of each successive running steps phases registration till the $60^{\text {th }}$ meter of the distance was realized with the help of tensometric complex and a special equipment. A comparative analysis of different level female athletes' starting stride biochemical characteristics was held. Spatial characteristics of movements were analyzed according to the materials of high-speed video filming.

The held research helped to reveal typical examples of speed running biomechanical elements, determined by qualification, sex and age of the respondents. It turned out to be possible to define three main types of biomechanical constructions, which are characterized by specific peculiarities.

The first type reflects the highest indices of sprinting qualification. It is characterized by vivid power concentration, short time period of support reaction, which, as a rule, is shorter (80-90 ms), than the duration of the flying interval (110-130 ms). Vertical part of efforts curve doesn't have fluctuations and is characterized by a sharp peak at maximum. The rhythm of a starting stride in this case has the definite characteristics. The most distinctive feature of a starting rhythm is a quick decrease of support periods duration in terms of flying time increase.

The second type of running biomechanical structure is demonstrated by the female athletes, who have high power potential, but don't have a rational technique.

These factors condition the definite character of a vertical part of efforts with a distinct saddleback in the phase of amortization. This type of biomechanical structure is known for a longer duration of support reaction (110-120 ms) and almost equal time of flying interval. Starting speeding-up among such kind of runners doesn't have an effective rhythm and they need longer starting stride in order to achieve stable ratio of flying and support phases durations of the running steps. This type of the running technique leads to a leg muscles overload and is connected with extreme energy consumption. The main reason of such kind of biomechanical errors is in a rough leg position on the ground and incompetent amortization phase fulfillment of a support reaction.

The third type of dynamic and kinematic structure of sprinting is typical for female athletes of not high qualification. It is characterized by a gradual development of efforts during the support reactions, which have an extended maximum of a dynamic curve. The time of support reaction (130-150 ms) is longer, than the duration of the flying interval ( $80-100 \mathrm{~ms})$. The rhythm of running is not active enough as a result of not high efforts concentration.

An effective rhythm of a sprinter's starting stride is characterized by a gradual and quick ratio approximation of the flying and support time of a running step to the indices, typical for the running rhythm along the distance. The research results proved the hypothesis about qualitative differences of the starting stride rhythm as the system of the biochemical characteristics regulated proportions. Two types of the starting stride rhythm were revealed (table 1).

For the first type gradual (within 3-4 first starting steps) steps rate indices achievement, close to running along the distance, is typical.

The second type of the rhythm realizes distance steps rate, starting from the $2^{\text {nd }}$ step of the starting stride.

Rhythm disorders of the starting stride are seen in sequence violation of support intervals duration decrease, in terms of simultaneous, successive increase of flying time duration increase in the length of a running step. The analyzed dynamograms of different sprinters' support reactions vertical part running steps differ in the character of the curve leading edge. Rhythm violation is connected with amortization phase duration spreading and irregularity of efforts increase during support reactions till maximum. These dynamic processes are determined by the factors of kinematic order. These factors are the following: an optimal starting pose choice, a low trajectory of swing-up foot movement during the first 
step, angles optimization in hip, knee and ankle joints in each successive step in a starting stride, in terms of correspondence with a sprinter's level of speed-power readiness.

Table 1 - Time characteristics of the running steps of two types of starting stride among female sprinters

\begin{tabular}{|c|c|c|c|c|c|c|c|c|c|c|c|c|}
\hline \multirow{2}{*}{$\begin{array}{c}\text { Type of } \\
\text { starting } \\
\text { stride }\end{array}$} & \multirow{2}{*}{$\begin{array}{l}\text { Phase of } \\
\text { the running } \\
\text { step }\end{array}$} & \multicolumn{11}{|c|}{ Number of a step } \\
\hline & & 2 & 3 & 4 & 5 & 6 & 7 & 8 & 9 & 10 & 11 & 12 \\
\hline \multirow{3}{*}{1} & Support, ms & 160 & 150 & 135 & 120 & 110 & 100 & 105 & 100 & 100 & 95 & 90 \\
\hline & Flight, ms & 70 & 90 & 95 & 105 & 115 & 115 & 120 & 120 & 120 & 125 & 130 \\
\hline & Step, ms & 230 & 230 & 230 & 225 & 225 & 220 & 225 & 220 & 220 & 220 & 225 \\
\hline \multirow{3}{*}{2} & Support, ms & 160 & 140 & 130 & 125 & 110 & 110 & 90 & 90 & 85 & 85 & 80 \\
\hline & Flight, ms & 60 & 80 & 90 & 95 & 105 & 120 & 125 & 130 & 135 & 135 & 140 \\
\hline & Step, ms & 220 & 220 & 220 & 220 & 215 & 220 & 215 & 220 & 220 & 220 & 220 \\
\hline
\end{tabular}

For competitive structure of female athletes' running study at 100 meters distance during AllRussian competitions using the system of electronic timing and video the following parameters were registered: steps tempo and length, individual speed at the parts of the distance o-30 m; 30-60 m; 60-80 m; 80-100 $\mathrm{m}$. The structures, which define power readiness, were studied with the help of polydynamometry and jumping tests. Among the respondents there were 45 female athletes (qualification: the $1^{\text {st }}$ categorymaster of sports) whose results range was 10.9-12.2 $\mathrm{s}$.

$100 \mathrm{~m}$ running strongly correlates with the average speed of running at the considered parts of the distance $(r=0,94-0,96)$, weakly correlates with an absolute and relative steps length $(r=0,22)$, correlates with steps rate $(\mathrm{r}=0,55)$. Taking into account the received results, regression equation was used and average statistical indices of distance parts overcoming according to time for the definite result were created.

At $100 \mathrm{~m}$ distance the differences between masters of sports and candidate masters of sport according to the average steps' length were registered. Among all three qualification groups there were valid $(\mathrm{P} \leq 0,05)$ differences in running steps tempo at $100 \mathrm{~m}$ distance. Qualification peculiarities at the distance of the starting stride according to the average length of the steps in this case were not significant. Moreover, the female athletes of all qualifications had almost the same average module of the step, which was 1,87 relative units. The step module was defined as step length to leg length ratio. At the distance of the starting stride $(0-30 \mathrm{~m})$ the average running speed weakly correlates with the step's length $(\mathrm{r}=0,25)$ and validly with the frequency of the steps $(\mathrm{r}=0,56)$.

At $30-60 \mathrm{~m}$ distance steps rate correlates with the speed of running $(\mathrm{r}=0,54)$ and increases to maximum. Steps length at this distance changes insignificantly and has a weak correlation $(r=0,18)$ with the average speed of running. In the compared qualification groups of female athletes, the step module 
corresponds with 2,35 relative units.

At the distance of 6o-80 $\mathrm{m}$ there were valid differences between the values of steps relative length among female athletes of the following groups: master of sports-candidate master of sports and the $1^{\text {st }}$ category- candidate master of sports. At the considered distance the speed of running correlates with a relative steps length $(r=0,62)$ and with the average rate of steps $(r=0,48)$. There is a negative interconnection between steps length and rate $(r=0,19)$. At this part of $100 \mathrm{~m}$ distance there are compensatory changes in the running technique in the structure of the running step because of fatigue: step length increases in terms of tempo decrease. The speed of running as a result of this compensation in comparison with the previous part almost doesn't decrease. The step module among female athletes is in the average 2,38 relative units.

At the final part of 80-100 $\mathrm{m}$ there was further running tempo decrease. At the same time, tempo decrease is not compensated by steps length increase; speed decreases by $2-4 \%$ and moderately correlates with the steps length $(r=0,36)$ and rate $(r=0,45)$. The differences between the groups of female athletes (the $1^{\text {st }}$ category -candidate master of sports) are demonstrated in tempo indices, between Candidate master of sports-master of sports group in steps length. The step module is 2,44 relative units. The held analysis helped to define three main types of female sprinters with different leading components of 100-meter distance overcoming. The first type athletes run with the help of relatively "short" step: the ratio of the average steps length to the tempo is 1,10-1,13 relative units. The second type athletes run with the help of "lengthened" step (1,23-1,27 relative units). The third type athletes in comparison with two first groups take the average position in length and rate of steps and have the following relative steps length 1,16-1,22 relative units. $80 \%$ of the whole number of respondents, who took part in the research, belong to this type. With the help of correlation analysis, it was underlined that among the female athletes, who have different qualifications in 100 meters running, results correlate validly with the values of an optional maximum isometric and relative legs muscles power $(\mathrm{r}=0,62-0,83)$. The values of the relative and maximum power of the lower extremities' muscles among female athletes of different qualification differ validly $(\mathrm{P}<0,05)$.

Demonstrated within 0,1 sec explosive power indices of legs muscles are closely connected with the time of running $100 \mathrm{~m}(\mathrm{r}=0,64-0,83)$. The demonstrated results at $100 \mathrm{~m}$ distance correlate validly with the results during testing with the help of a tenfold standing jump in relative $(\mathrm{r}=0,78)$ and absolute $(\mathrm{r}=$ 0,65 ) values.

Then received during the research results showed high informativity and indices validity (demonstrated within $0,1 \mathrm{sec}$ ) of maximum isometric, relative and explosive isometric power for power abilities estimation among female athletes. The indices values, registered among female athletes of different qualification levels, can be model characteristics for individual correction of the training programs. Taking into consideration the received results individual models of running structure for the planned result were created. In terms of female athletes' current physical state, their psychophysiological peculiarities, principle approaches to the training effects correction were determined.

\section{Conclusion}

Using studied informative biomechanical characteristics on the basis of experimental work results for different objectives realization of an effective technique teaching, we see great opportunities of female sprinters' motor function diagnostics means.

The realized approach helps to impose restrictions on biomechanical information interpretation in terms of the definite pedagogical demands. For example, the results about the character of the efforts during support reactions, indirectly proving power potential, can help to define the type of dynamic structure and define the program of its development. But they don't give an opportunity to make any conclusion concerning the mechanisms of muscular activity. For this purpose, other, more "responsive" methods of hardware diagnostics are necessary, in particular the methods of electromyography in combination with high speed video filming. 
The research results demonstrate an evident importance of urgent information about time and power characteristics of the running steps during sprinters' technical improvement process. With the help of this information it becomes possible to reveal the reasons of individual technical errors and chose adequate exercises for their correction.

The information about the speed of running at the separate parts of the distance can be interpreted during comparison with the results of rhythmic running characteristics registration of a female athlete of different qualification and a female athlete from track and field athletics national team.

At the same time, it is natural to suppose that new technologies of urgent information receiving should be developed in accordance with the demands of training high-class sprinters. The results of the research can be interesting in terms of stability of running steps rate as an important factor of an optimalrhythmic structure of sprinters' starting stride organization. Great prospects has computer analysis of the whole range of mentioned above informative biomechanical characteristics, realized for personal and typological statistical regularities of these characteristics revelation under the influence of urgent and longterm pedagogical influences.

\section{References}

1. Mirzoev O.M. Kinematic characteristics of technical mastery analysis among highly-qualified athletes in 100 meters running. Sovremennye tendencii razvitiya legkoj atletiki $v$ mire: sport vysshih dostizhenij I podgotovka rezervov: sbornik nauchno-metodicheskih materialov Vserossijskoj nauchnoprakticheskoj konferencii s mezhdunarodnym uchastiem, posvyachennoj 8o-letiyu obrazovaniya kafedry teorii I metodiki legkoj atletiki imeni N.G. Ozolina [Modern tendencies of athletics development in the world : high results sport and reserves training : collection of scientific-methodical materials of All-Russian scientific-practical conference with the International participation, dedicated to the $80^{\text {th }}$ anniversary of athletics theory and methodology department named after N.G. Ozolin]. Moscow: Russian State University of Physical Culture, Sport and Youth and Tourism. 2017: 13-23 (In Russ.).

2. Elena A. Anisimova, Andrei N. Katenkov, Ludmila D. Nazarenko. Factors, which influence the effectiveness of 400 meters running among qualified 17-20-year-old female athletes. Pedagogico-psyhological and medico-biological problems of physical culture and sport = Pedagogikopsihologicheskie I mediko-biologicheskie problemy fizicheskoj kul'tury I sporta. 2017; 12(3): 24-30. DOI: 10.14526/o3_2017_231 (In Russ., In Engl.).

3. Mironenko I.N. Modern tendencies and biological aspects of sprinting development in the world. Sovremennye tendencii razvitiya legkoj atletiki $v$ mire: sport vysshih dostizhenij I podgotovka rezervov: sbornik nauchno-metodicheskih materialov Vserossijskoj nauchno-prakticheskoj konferencii s mezhdunarodnym uchastiem, posvyachennoj 8o-letiyu obrazovaniya kafedry teorii I metodiki legkoj atletiki imeni N.G. Ozolina [Modern tendencies of athletics development in the world : high results sport and reserves training : collection of scientific-methodical materials of All-Russian scientific-practical conference with the International participation, dedicated to the $80^{\text {th }}$ anniversary of athletics theory and methodology department named after N.G. Ozolin]. Moscow: Russian State University of Physical Culture, Sport and Youth and Tourism. 2017: 70-78 (In Russ.).

4. De Ruiter C.J., De Haan A. Similar effects of cooling and fatigue on eccentric and concentric force-velocity relationships in human muscle. Journal of Applied Physiology. 2001; 90: 2109-2116.

5. Pincivero D.M., Gandaio C.M., Ito Y. Gender-specific knee extensor torque, flexor torque, and muscle fatigue responses during maximal effort contraction. European Journal of Applied Physiology. 2003; 89: 134-141.

Bragada J.A., Santos P.J., Maia J.A., Colaco P.J., Lopes V.P., Barbosa T.M. Longitudinal study in $3000 \mathrm{~m}$ male runners: Relationship between performance and selected physiological parameters. Journal of Sports Science and Medicine. 2010; 9: 439-444. URL: http://www.jssm.org/vo19/n3/12/v9n3-12pdf. pdf.

Davison R.R., Someren K.A., Jones A.M. Physiological monitoring of the Olympic athlete. Journal of Sports Science. 2009; 27(13): 1433-1442. DOI: 10.1080/02640410903045337.

Manzi V., Iellamo F., Impellizzeri F., D’Ottavio S., Castagna C. Relation between individualized training impulses and performance in distance runners. Medicine and Science in Sports and Exercise. 2009b; 41(11): 2090-2096. DOI: 10.1249/MSS.obo13e3181a6a959.

Mujika I., Padilla S. Detraining: Loss of training-induced physiological and performance adaptations. Part II: Long term insufficient training stimulus. Sports Medicine. 2000; 30(3): 145-154. 
DOI: 10.2165/00007256-200030030-00001.

Gould D., Greenleaf C., Guinan D., Chung Y. A survey of U.S. Olympic coaches: Variables perceived to have influenced athlete performances and coach effectiveness. The Sport Psychologist. 2002; 16: $229-250$.

Gould D., Greenleaf C., Guinan D., Dieffenbach K., McCann S. Pursuing performance excellence: Lessons learned from Olympic athletes and coaches. Journal of Excellence. 2001; 4: 21-43.

Bonacci J., Chapman A., Blanch P., Vicenziro B. Neuromuscular adaptations to training, injury and passive interventions: Implications for running economy. Sports Medicine. 2009; 39(11): 903-921. DOI: 10.2165/11317850-000000000-00000.

Cavagna G.A., Mantovani M., Willems P.A., Musch G. The resonant step frequency in human running. Pflugers Archiv - European Journal of Physiology. 1997; 434(6): 678-684. DOI: 10.1007/ s004240050451.

Fletcher J.R., Esau S.P., MacIntosh B.R. Changes in tendon stiffness and running economy in highly trained distance runners. European Journal of Applied Physiology. 2010; 110(5): 1037-1046. DOI: 10.1007/s00421-010-1582-8.

Hunter I., Smith G.A. Preferred and optimal stride frequency, stiffness and economy: Changes with fatigue during a 1-th high-intensity run. European Journal of Applied Physiology. 2007; 100(6): 653-661. DOI: 10.1007/s00421-007-0456-1.

\section{Submitted: 17.10.2018}

Aleksey V. Meshcheryakov - Candidate of Biological Sciences, Associate Professor, Ulyanov State Pedagogical University, Ulyanovsk, Russia, the 100 Anniversary of V.I. Lenin's Birth Square, House 4, 43270o, e-mail: aleksei236632@yandex.ru 